\title{
Ur-writings: A geophonographic fiction
}

Will Schrimshaw, Artist, Lecturer, Performing Arts Department, Edge Hill University, St. Helen's Road, Ormskirk, Lancashire, L39 4QP, UK. Email: will@willschrimshaw.net

\section{(C) ISAST}

Manuscript received 24 September 2014

\begin{abstract}
Geophonography is a practice of sonifying the geological record, of tracing what Friedrich Kittler referred to as "signatures of the real". The aesthetic efficacy of techniques for audifying and visualising data derived from geological materials is discussed within the context of Ur-writings, a piece by the author first exhibited in 2013. Tracing a line through the work of Freud, Adorno, Kittler, Ballard and Derrida, geophonography is positioned within a cultural context that has continued to draw inspiration from speculations upon the relation between earth and mind.
\end{abstract}

\section{Introduction}

Rising up from a grille in the pavement outside the Science Friction gallery, Copenhagen, a deep, repetitive noise resembling the sound of vinyl run off, a peculiar engine or mining operation, fills half of the street. Over a period of forty-three minutes, subtle changes in rhythm and timbre occur in the composition of the intense, brutal noise. This piece marks the entrance to the Pitch Drop exhibition---taking its name from Thomas Parnell and John Mainstone's famous experiment documenting the viscosity of bitumen---focusing upon the durations, nature and geophysical origins of matter implicated in the perceived immateriality of media arts practice.[1] Ur-writings is a single channel audio piece first exhibited in the Pitch Drop exhibition at Science Friction in 2013 and is part of a series of "earth works" and experiments that $I$ had been undertaking in various media since 2011. Ur-writings is a single instance of a broader experimental practice of geophonography, a term used to describe diverse sonifications of the earth in artistic practice. Katie Patterson's As the World Turns (2011) and Langjökull, Snæefellsjökull, Solheimajökull (2007), Doug Aitken's Sonic Pavilion (2009) and Jens Brand's G-player (2004-7) can all be taken as examples mapping a broader terrain of geophonographic practice.

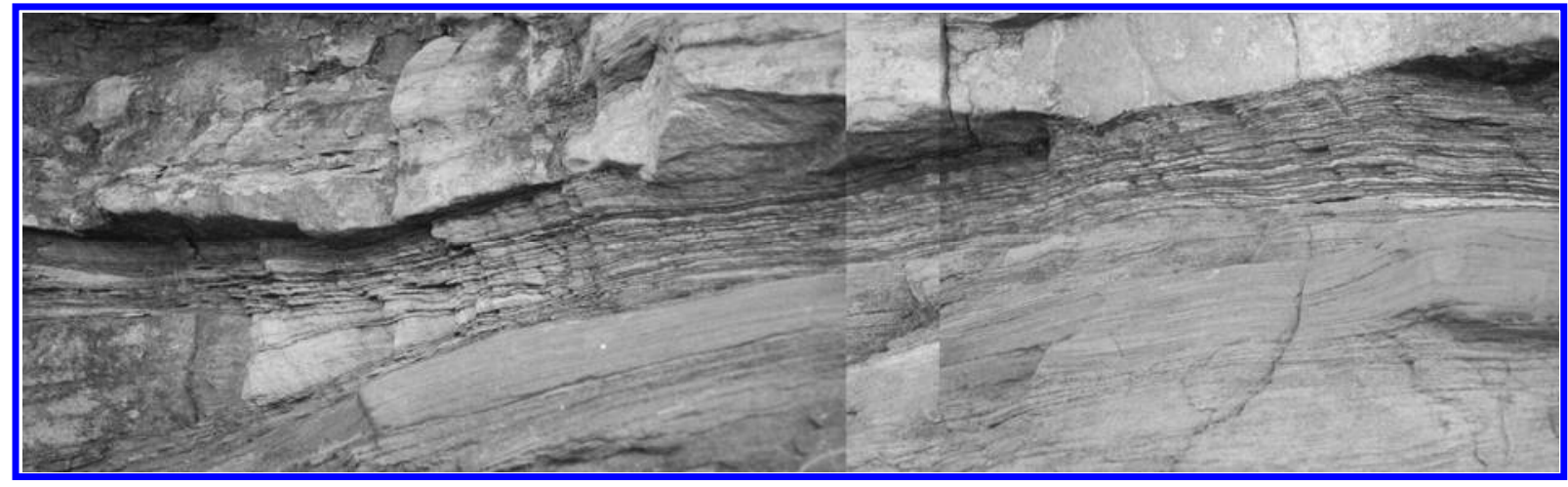

Fig. 1: Cropped excerpt from the image used in the production of Ur-writings. ( William Schrimshaw) 
There are two stages to the discussion that follows: the first provides a theoretical context outlining the ideas implicated in the production of Ur-writings, the second outlines the technical process involved in the production of a number of artworks. It is with regard to the theoretical context established herein that this article operates as a fiction in two senses: firstly, the subtitle of this paper refers to Robert Smithson's Strata: a geophotographic fiction (1977), which poetically "decompresses" the geological record through the use of alternating horizontal images of the fossil record and rows of text aimed at unearthing "memory at a chthonic level" (Smithson 1996: 77). Secondly, this paper constructs a kind of fiction or "imaginary situation" in which fragments of theoretical texts are approached "not [as] the object, but the instrument of the elucidation." (Meillassoux 2007: 64-5). Accordingly it is not my intention to present readings of key authors strictly in keeping with their own projects, but rather to mine concepts, to excise fragmentary ideas generative of a productive fiction, fragments that become instrumental in elucidating the conceptual conditions of the art works described herein.

While the exhibition of Ur-writings concluded a phase of geophonographic experimentation, the technical procedure used in its production---converting images of rock samples into sound by mapping pixel values indicative of depth to the amplitude of individual audio samples---underwent several alterations. Each alteration produced objects in various media. These various visual objects, the processes used in their production and the reasons for their eventual abandonment in favour of a single channel audio piece are also discussed below.

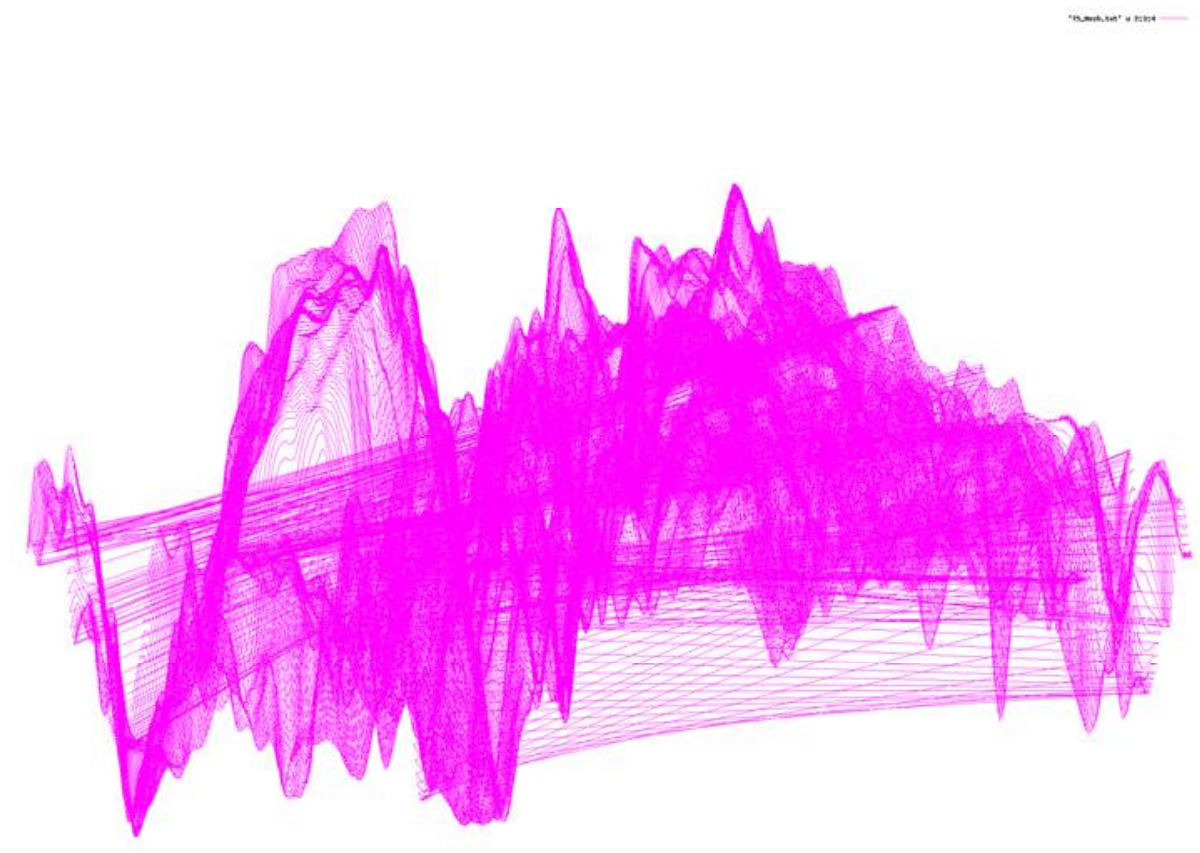

Fig. 2: Visualisation of .obj file derived from a digital image of a rock sample. (@) William Schrimshaw) 


\section{Geotrauma: an impression of the earth}

In 2011 I moved from central Newcastle upon Tyne to the nearby coast. On daily walks along beaches and cliffs rocky outcrops breaking the otherwise smooth surface of Longsands bay became a focal point. These outcrops indicate an ongoing record being compiled beneath the surface, comprising the strata subtending the order of everyday life. Through coincidence, around the time of my relocation I had been exploring the concept of "geotrauma"; Freudian in origin, a speculative implication of the earth in the obscure operations of the unconscious, the theory of geotrauma claims that "in the last resort, what has left its mark on the development of thought must be the history of the earth" (Brassier 2007: 223).[2] Running with some of Freud's wildest speculations from Beyond the Pleasure Principle, geotrauma locates the pre-symbolic psychoanalytical order of the real not in pre-critical or pure phenomenological experience, the body or flesh, but in the terrestrial body at large and its ongoing morphology. Thought is not conceived as having evolved in isolation from the earth's own ongoing developments or cosmic contingencies and the latter is accordingly figured as having left an obscure imprint upon the evolution of thought. The compulsion to return daily to the cliffs, where sedimentary processes continuously form folds, lines and protrusions periodically rupturing the otherwise smooth curvature of the surface, led to an increasing suspicion that this was not all that was being penetrated, that these outcrops indicated a more profound protrusion into the mind. Located within an artistic context, such concerns have a distinctly Smithsonian resonance, whose thoughts regarding A Sedimentation of the Mind (1968) and "abstract geology" speculated upon analogous erosions of earth and mind, (Smithson 1996: 100-113).

At the coast we find two sites of "traumatic" origin marking a bifurcation: the sea from which animals once crawled, breaking with previous evolutionary strands, moving along new evolutionary trajectories, and that of a more ancient origin in the geological and inorganic, the inorganic to which all organic life, according to Freud (1991: 310-311), seeks to return. This compulsion to return and repeat is in psychoanalytical theory an indication of trauma, the eruption of the traumatic real---that which is in excess of and not containable within symbolic representations---that is bound and consolidated through repetition. The atavistic compulsion to return to the originary sites of the ocean and outcrops of the earth's inorganic substrates is, according to this speculative psychoanalytical framework, an attempt to come to terms with traumatic origins, with the oblivion from which the conditions of thought emerged and to which it will inevitably return. The coast presents us with two sites or sources of originary noise: that of the sea---described as such in the work of both Schafer (1994: 15) and Serres (1999)---but also the traces of a noise rarely sounded, obscure and illegible inscriptions upon the surfaces of rocks, empty traces devoid of sense yet nonetheless catalytic. Insofar as these inscriptions signify nothing, being intended for neither sense nor sound, they are---in contrast with the sound of the sea that functions as a sign and readily conjures an image---more easily aligned with the void or the "nothing" that is characteristic of the real. The compulsion to repeat and return that is driven by sites embodying the ruptures of a geotraumatic real find an analogue in the repetitive techniques automated in the production of Ur-writings as well as in the aesthetics of the final piece whose repetitive structure and phasing is akin to the revolutions at the end of a phonograph record whence obscure and unintentional patterns arise from accidental inscriptions.

While developing Ur-writings, I found myself listening to the piece as I would a vinyl that I had forgotten to remove once the music had ended; despite their repetitive, brutal aesthetic, such sounds can slip into the background, becoming the object of a less active if not entirely unconscious mode of listening. There is something trance inducing about these kinds of sounds, the way all sense of time can be lost in them once the music has finished and the needle begins repeatedly tracing the final inscriptions never intended for sense or sound. I often find myself thinking that these sounds seem to index a memory pointing to something long 
forgotten, a distinctly Ballardian sensation.

In Ballard's The Drowned World, repetitive "scratching noises" and "a deep slow drumming" (Ballard 2008: 36) emitted from a portable record player are used in therapeutic attempts to bind or control traumatic nightmares of an "archeopsychic past" (Ballard 2008: 43), as the characters in the novel regress down the evolutionary chain due to dramatic changes in the global eco-system. The phonographic record in Ballard's novel has a particular significance as a "row of parallel black discs" is depicted as "a model of a neurophonic spinal column" (Ballard 2008: 44). Moving backwards, indexing the records with a finger or a needle, one plays in reverse a kind of obscure soundtrack accompanying evolution.

The speculative notion of significance here is the link made to a (geo-)phonographic record accompanying regression or return to an "original traumatic situation" (Ballard 2008: 43). The obscure rhythms and noises encoded upon the records in Ballard's novel index "archaeopsychic past", an internalised memory of the outside that for Ballard is the evolutionary history of the mammalian organism but for Freud the inorganic matter of the terrestrial body in its relationship with the sun, to which the organism is driven to return. It is this notion of an archeopsychic past or more broadly an originary exteriority indexed by phonographic techniques that has driven the development of the geophonographic method to be described in more detail below, the conceptual trajectory of which can be schematised as follows:

$$
\text { phonography }>>\text { writing }>>\text { exteriority }>>\text { real. }
$$

To clarify this conceptual schema, establishing a connection between phonography, exteriority and the real, a line will be traced through the work of Theodor Adorno, Jacques Derrida and Friedrich Kittler. This tracing will establish a line connecting the phonographic "ur-images of sound" (Adorno 2002: 280), the "exteriority of writing in general" (Derrida 1997: 14) and the "signatures of the real" (Kittler 1999: 118).

\section{Ur-writing}

Speculation on the obscure inscriptions impressed by phonographic recording lead Theodor Adorno to describe these illegible scribbles as "script-like Ur-images of sound" (Adorno: 2002, 280), identifying these impressions as a form of originary inaudibility, anterior and exterior to sonic experience. Adorno went further in stating that "through the curves of the needle on the phonograph record, music approaches decisively its true character as writing" (Adorno 2002: 280). Writing is thus conceived as originary anteriority to sound. Herein Adorno's comments regarding the true character of music are extended to sound in general, updating Adorno's thoughts to encompass the contemporary proliferation of sound in the arts. Here we should venture a further extension/misappropriation of Adorno's speculation on the record. Actively confusing geological and phonographic records we can divert Adorno's description of a record "covered with curves, a delicately scribbled, utterly illegible writing, which here and there forms more plastic figures for reasons that remain obscure" (Adorno 2002: 277), a description that could refer equally to earth or shellac. It is the tracing of obscure curves and illegible writing, in combination with the confusion of the geological and phonographic that outlines the geophonographic method, playing back fragments of the geological rather than the phonographic record.

Adorno's specific concerns and conception of writing remained bound to language and sense---with phonographic inscriptions constituting a natural, immediate language with no need of "mere signs" (Adorno 2002: 280)---yet for the purpose of elucidating the conceptual framework underlying the geophonographic 
method this writing needs to be excised from sense and semantics, emptied of presence, while salvaging from Adorno's argument the insightful suturing of sound to an originary, anterior form of writing, not as sign but illegible, empty trace. In performing this salvage operation we reclaim a kind of conceptual component for bridging sonic or phonographic practice and a notion of exteriority that, against the sonification of presence, ultimately privileges epistemological efficacy over phenomenological sufficiency. The most extensive critique of the metaphysics that constrained Adorno's speculations comes from the work of Jacques Derrida. To excise this writing from sound and sense we can pass the writing that for Adorno constitutes music's---and by extension sound's---true character through a kind of Derridean filter unbinding sense from sound and puncturing presence, thereby providing an opening onto exteriority. To assert sound's true character as writing is to---anachronistically---attest to Derrida's assertion that sound and the interiority of orality is always already punctured by an "eruption of the outside within the inside" (Derrida 1997, 34). What phonography reveals is that sound was always already a form of writing or a trace.

The claim being made here is that an assertion of sound's true character as writing is to submit sound to "the exteriority of writing in general" (Derrida 1997: 14) a submission contrary to dominant trends and figures of interiority within sound art. The consequence of this assertion that grounds sonic experience in silent "scriptlike Ur-images of sound" is that, despite appearances, sound retains an immanent connection to exteriority through its "true character as writing," that which exists in excess of perception within the domain of an unintuitable real. This connection is, however, a silent one that takes the form of a kind of ur-writing that is not given to experience or intuition and so must be unearthed by other means. Before attempting an account of the status of this ur-writing, the characteristic exteriority of "writing in general" posited by Derrida should briefly be clarified so as to highlight a point of disjunction.

Through a critique of Saussure, Derrida (1997: 30-65) shows how writing has been considered secondary and a somewhat impoverished form of language, coming second to sound but specifically speech. Furthermore, the voice and specifically hearing oneself speak is critiqued by Derrida as the cornerstone of a metaphysics of presence founding phenomenal interiority and a unified sense of self. Writing attains its characteristic exteriority insofar as it is a means of externalising and recording language. Derrida's critique of the metaphysics of presence claims that this primacy of voice binding sound and sense, unifying the sense of self, is illusory, and it is writing which is fundamental and constitutes the architecture of soul and subject. It is through a concept of writing built upon the emptiness of what Derrida calls "spacing" and "trace"---both concepts indicating "an irreducible absence" marked by writing in opposition to the fullness or presence of the voice and the immanence of sound and sense---that writing's characteristic exteriority is most starkly highlighted, as a being both empty and exterior to sound, sense and intention (Derrida 1997: 47). Rather than critique Derrida's attack on the significance of sound and sonorous metaphysics it is herein considered something to be extended, insofar as---when supplemented with Adorno's insight regarding the "true character" of sound---it provides an opportunity for a break with the predominance of an encircling figure of interiority and an essentialising of experience within sound-arts discourse. While Derrida helps to clarify the consequences of asserting sound's true character as writing, we must---against Derrida, and specifically his resistance to any alignment of the empty trace with an empirical mark---assert a connection between the exteriority of writing and the real, a connection made by Friedrich Kittler. What brief recourse to Kittler will show is that Derrida's preliminary identification of writing with exteriority can be consequently expanded and "grounded"---a grounding of the trace that geophonography carries out in a very literal way---creating a space for accidental, unconscious and inhuman writing constituting a mark of the real. 


\section{Signatures of the real}

The lines traced in the geophonographic method can, insofar as the result is a sonification of inscriptions never intended for sound or sense, be understood as what Kittler has called "signatures of the real" (1999: 118). Kittler famously maps what he describes as the "ur-media" of phonograph, film and typewriter onto Lacan's three "orders" of psychoanalytical phenomena: the real, the imaginary and the symbolic, respectively. Kittler summarises the Lacanian "orders" as follows:

the symbolic now encompasses linguistic signs [...] The imaginary, however comes about as the mirror image of a body [...] of the real nothing more can be brought to light than what Lacan presupposed---that is, nothing. It forms the waste or residue that neither the mirror of the imaginary nor the grid of the symbolic can catch. (Kittler 1999: 15-6).

Notwithstanding the peculiarities of Kittler's mapping or limitation of phonograph and film to the real and imaginary respectively, the former provides a useful link in describing the peculiar desire that arose in me to trace the "insignificant" or meaningless contours found on the surface of sedimentary protrusions around the North East of England. It is with a certain morbid fascination that one is drawn to such lines, written in stone over an unintuitable duration and committed to a record in which the existence of humanity will undoubtedly be only the briefest of instants. On the similarly morbid topic of the peculiar lines found intersecting the human skull, Kittler describes how:

A trace or path appears where the frontal and parietal bones of the "suckling infant" [...] have grown together $[\ldots]$ the naked eye is now able to read the coronal suture as a writing of the real [...] Before [Rilke], nobody had ever suggested to decode a trace that nobody had encoded and that encoded nothing [...] Ever since the invention of the phonograph, there has been writing without a subject. It is no longer necessary to assign an author to every trace, not even God. (1999: 44).

It is precisely this "nothing" that links the phonographic tracing of lines never written to the nothing that characterises Lacan's real; where for Kittler an instance of the real as pre-symbolic residue is found in the sutures of the skull, geophonography breaks with both Lacan and Kittler, following a speculative trajectory from the abject body or skull to the earth as a site of the real. This empty writing that encodes nothing constitutes a mark of the real written into an inorganic exteriority from which the organic emerged and to which, following Freud, it is driven to return. In decoding a writing that no intention belies, in following insignificant lines that move from the skull to the earth, an initially Derridean evacuation of presence from writing is forced beyond the text to a conclusion impressed upon inorganic exteriority.

\section{Geophonography}

In what follows I will go into a little technical detail regarding what I have been referring to as the geophonographic method of which Ur-writings is a single instance. The geophonographic method responds to a personal desire to drag a needle across the surface of the earth and the suspicion that to do so entails indexing an archival substrate immanent to one's own mind. A three stage geophonographic method for tracing the earth's auto-affective impressions was developed as a means of sonifying inscriptions never intended for sense or sound. The three stages, visualised in fig. 3, are as follows:

1. Photographic production of a non-site.

2. Basic image analysis and conversion: each row of (grayscale) pixels is converted into a waveform.

3. Sequential or simultaneous playback of all waveforms derived from photographic non-site. 
Depending upon the choice of either (a) simultaneous or (b) sequential playback at stage three the resulting sound files produced from a $29537 \times 2387$ image at a sample rate of $44.1 \mathrm{kHz}$ are either under one second or forty three minutes in length respectively, being equivalent to (a) dragging 2387 needles across a patch of earth at once or (b) dragging a single needle 2387 times without overlap across the same patch of earth. The pixels of a grayscale image (see fig. 1) are indexed from left to right, top to bottom. As the grayscale values of the image are indicative of the depth of the various contours and indents found upon a rock's surface, these grayscale values are then converted into amplitude values---amplitude constituting the vertical axis of timedomain representations of sound---for individual samples in the composition of an audio file. Through this method each line of pixels determines the contours of a waveform. In the production of Ur-writings, each of the 2387 waveforms produced through the above method was adjoined serially, producing a single mono file. It is in the process of repeated tracing that we find the first instance of significant repetitions, constituting a kind of binding of an originary geotrauma. It was through happy coincidence that the waveforms produced through this method resembled the kinds of repetitive patterns and rumbles found in the insignificant grooves of vinyl run off, the empty traces whose sound presents only an absence of content and intention. 


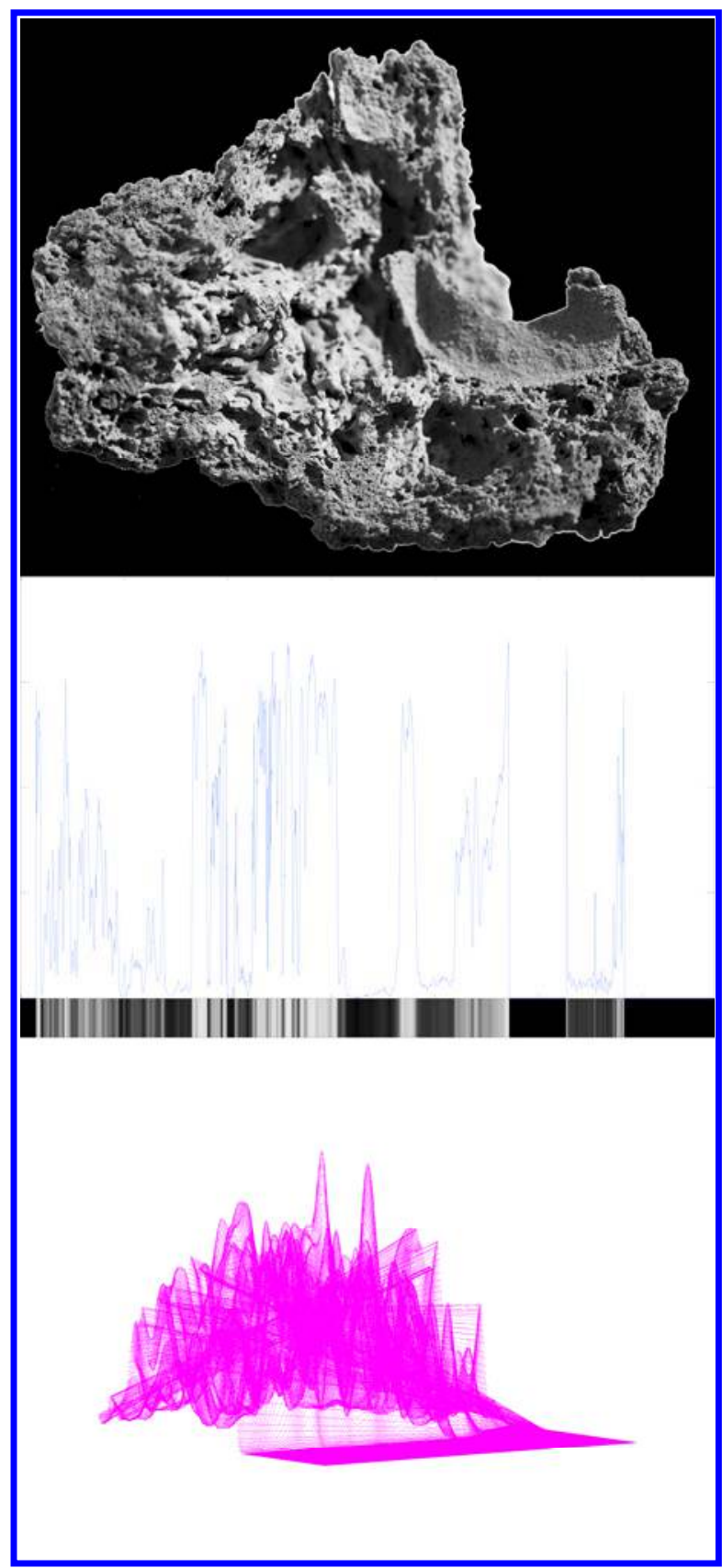

Fig. 3: Visualisation of the three stages of the geophonographic method. (@ William Schrimshaw)

This project had begun with a desire to drag a needle across the surface of the earth, so as to trace or index these signatures of the real. Having produced a method that fulfilled this desire a period of experimentation was entered into, transforming the data produced by the geophonographic method into a number of different outputs. An early instance of experimenting with outputs produced a version of Ur-writings that was spectrally reduced by periodically freezing only the most dominant fifteen frequencies of the overall spectrum, which resulted in much softer and simpler drones varying slowly over the course of the piece. This process, however, resulted in a loss of the brutal aesthetic reminiscent of the geological outcrops that had originally been traced. 


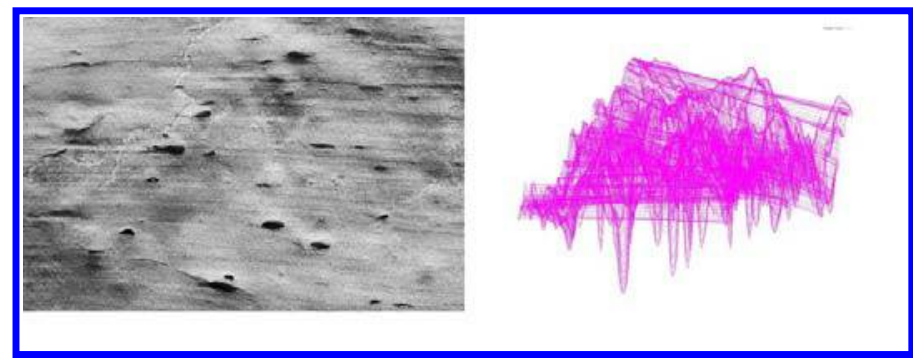

Fig. 4: Conversion of photographic non-site into 3D .obj. (ㅇ William Schrimshaw)

Having extracted a large amount of data from a variety of rock surfaces I had begun experimenting with forms of visualisation that might aid understanding of the process involved in the geophonographic method. The data extracted through basic image analysis could just as easily be converted into a 3D model (such as an .obj file, see fig. 2) as a waveform, and so ready access to a CNC machine gave me the opportunity to reinscribe a number of the surfaces that had been traced into new materials, such as wax and wood. After and extensive period of exploring this technique, never quite being happy with the results, I realised that the objectification of this process brought with it an unwelcome punctuation, an aestheticization of idea and desire that resulted in a series of premature completions and objectifications that consistently disappointed. In a manner akin to coagulation through contact with the air, the opening of this simple idea to differing methods of objectification resulted in a slowing, congealing and eventually the stalling of an idea that had previously flowed and driven a period of intense research and production. It was only after proceeding down numerous dead ends that I returned to the most basic form of output, the rawest of the tracings that simply mapped the grayscale pixel values indicative of depth and the contours of the rock surface onto a numerical range of $-1--+1$ that would be suitable for "audification" and most closely matched the phonographological origins of this work (Dombois \& Eckel 2011).

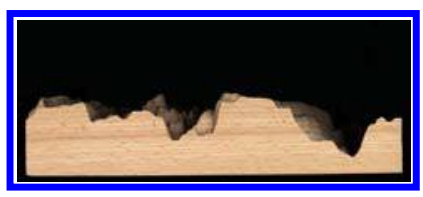

Fig. 5: Side view of a wood-cut, foregrounding a single waveform cut into wood with CNC. (@) William Schrimshaw)

What this simple process of audification retained that various other methods of objectification lost was a sense of duration and process; when listening to the piece we grasp not the form or outline of a traced and absent object in its entirety---as we would when looking at the wood cuts---but rather follow or trace a line by listening, a line that could just have easily have been traced by a needle. The apparent "immateriality" and procedural nature of the sonic results seem to retain a certain openness or mobility of the original idea and desire, rather than foreclosing or granting it an apparent unity through solid objectification. 


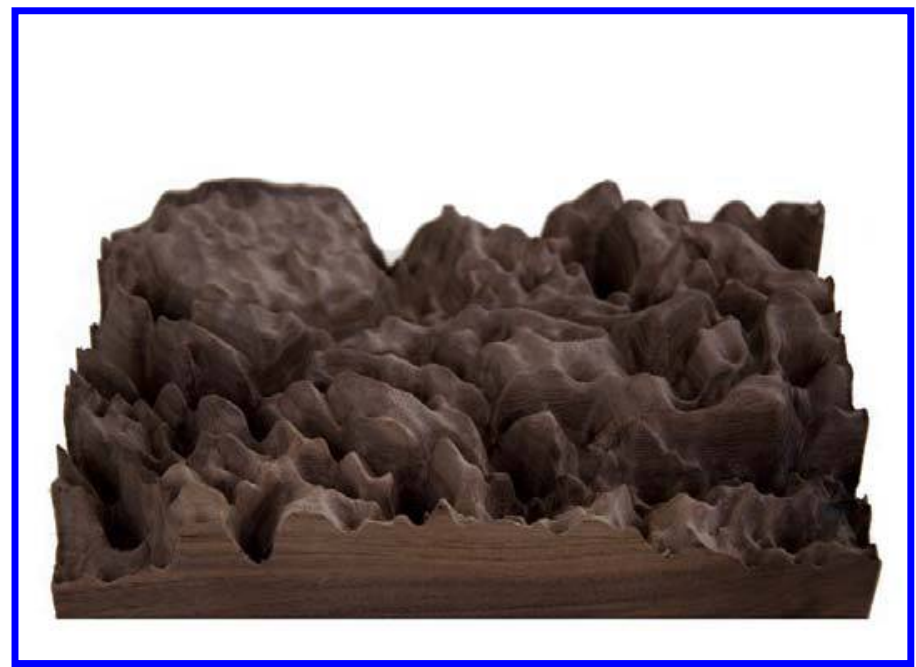

Fig. 6: Photographic non-site converted to three dimensional .obj and cut into walnut with CNC. (C) William Schrimshaw)

Fig. 7: Still from Trace Index (2014). ( William Schrimshaw)

\section{Infinite exchange}

Experimentation with various forms of aesthetic outputs had, while resulting in many futile experiments and much objective detritus, not been entirely unproductive. This repeated experimentation, enabled by the mutability of the dataset and its indifference to origin and aesthetic, foregrounded the process of abstraction and a kind of levelling brought about by digitisation as a process reducing object, aesthetic and origin towards what Badiou describes as "pure [quantitative] multiple as the foundation of presentation" (1999: 56). Amidst all this experimentation and reduction the earth became just one more romantic figure being clung to, 
one recording surface, one site of nonsensical or meaningless impressions conditioning sense from without. The sense of an overwhelming potential of aesthetic and objective outputs from data derived from the contours of geological protrusions, resulting in the stalling of the project's development for a number of months, was a reaction to the distinctive ontological register and oblivion through which the object is passed or filtered in digitization, a realisation that decoupled the data set equally from origin and output. Excised from its dependency upon the physical presence of an original object, the data set derived from a process of tracing constitutes a further iteration or peculiar conclusion of the Derridean trace. Decoupled from source and origin, devoid of aesthetic qualities, emptied of all presence, the quantitative data set becomes capable of what Peter Osborne (2010) calls "infinite exchange," accommodating infinite multiplication and indifference to media specific rendering.[3]

In response to this surfacing of a distinctive ontological register through repeated experimentation and an emergent indifference to a variety of outputs from the same data set in distinct media, I produced Trace Index (2014), a 47 minute video loop carrying out the same sequential tracing of values derived from the same data set used to produce Ur-writings. The video piece sequentially displays vertical grayscale stripes that move continuously across a floor-mounted screen, the intention being to create a wave-like motion, as if one is looking down upon the peaks and troughs of a wave---the same wave rendered as sound in Urwritings---rather than a more typical time domain representation of a waveform or pictorial projection. This technique was chosen to mirror the process of audification used in Ur-writings, maintaining a sense of the procedural at the expense of a coherent, consistent or unified image; in this instance it is the eye that is forced to trace a line. Seeking a kind of proximity to the empty trace, inaudible, unbound from the earth, decoupled on all sides and aesthetically impoverished, Trace Index formed a conclusion if not completion of the geophonographic project: a statement of the ontological indifference of the decoupled data set as a form of writing in general, unbound from qualitative effect or punctuation, a promiscuous medium indifferent to both origin and output rendered capable of infinite exchange.

\section{Notes}

[1] Pitch Drop took place at the Science Friction, Copenhagen, 20/11/13 - 04/12/13 and included new works by Will Schrimshaw, Rosemary Lee, Martin Howse, Anders Kølle and Jamie Allen.

[2] The concept of geotrauma features heavily towards the end of Fanged Noumena, a collection of Nick Land's writings (2011). What had drawn me to the concept was the tendency to dramatise the concept of geotrauma in sonic terms and to describe "subterranean" forces in terms of an obscure rumbling or murmur, as can be found in the work of Iain Hamilton Grant (2000).

[3] Osborne's notion of infinite exchange is a response to digital photography but is applicable to digitization in general.

\section{Bibliography}

Adorno, T. A. (2002) Essays on Music. University of California Press: Berkeley and London.

Badiou, A. (1999) Manifesto for Philosophy. Albany: SUNY Press.

Ballard, J. G. (2008) The Drowned World. London: Harper Perennial.

Brassier, R. (2007) Nihil Unbound: Enlightenment and Extinction. Hampshire and New York: Palgrave Macmillan. 
Derrida, J. (1997) Of Grammatology, Baltimore and London: The John Hopkins University Press.

Dombois F, Eckel G (2011) 'Audification', in Hermann T, Hunt A, and Neuhoff JG (eds.) The Sonification Handbook, Logos Publishing House. pp. 301-324.

Freud, D. (1991) 'Beyond the Pleasure Principle' in The Penguin Freud Library Vol. 11: On Metapsychology. London: Penguin.

Grant, I. H. (2000) 'The Chemistry of Darkness', Pli, 9, pp. 36-52.

Kittler, F. (1999) Gramophone, Film, Typewriter. Stanford: Stanford University Press.

Land, N. (2011) Fanged Noumena: Collected Writings 1987 - 2007. New York and Falmouth: Urbanomic and Sequence Press.

Meillassoux, Q. (2007) 'Subtraction and Contraction: Deleuze's Remarks on Matter and Memory', Collapse: Philosophical Research and Development, 3, pp. 63-107.

Osborne, P. (2010) 'Infinite Exchange: the social ontology of the photographic image', Philosophv of Photography 1:1, pp.59-68.

Schafer, R. M. (1994) The Soundscape: Our Sonic Environment and the Tuning of the World. Vermont: Destiny Books.

Smithson, R.(1996) The Collected Writings. Berkeley: University of California Press.

Serres, M. (1999) Genesis. Ann Arbour: The University of Michigan Press.

\section{Glossary}

Geotrauma: a concept found in the writings of Nick Land---building upon ideas found in Freud and Deleuze and Guattari---locating the emergence and development of thought in a continuum with geological and even cosmological history or evolution.

Non-site: Taken from the work of Robert Smithson, the creation of a non-site involves extracting, abstracting and relocating elements of a site, often rocks, in a new context. The non-site has been described as an "indoor earth work" abstract in appearance while still representing an actual site (Smithson 1996: 364).

Geophonography: A broad term referring to diverse artistic methods of sonifying the earth or portions of it. Real: variously understood to refer to the pre-symbolic, objective and indifferent rather than subjective constructions.

Ur-writing: meaning originary writing, also the name of an artwork created by the author.

\section{Biography}

Will Schrimshaw is an artist and musician based in Liverpool, UK. He is Lecturer in Music and Sound at Edge Hill University. 